Jose Pedrito M. Magno, MD Josefino G. Hernandez, MD² Daryl Anne A. Del Mundo, MD²

'Department of Otorhinolaryngology Philippine General Hospital University of the Philippines Manila

${ }^{2}$ Department of Otorhinolaryngology College of Medicine - Philippine General Hospital University of the Philippines Manila

Correspondence: Dr. Daryl Anne A. Del Mundo Department of Otorhinolaryngology Ward 10, Philippine General Hospital

University of the Philippines Manila

Taft Avenue, Ermita, Manila 1000

Philippines

Phone: (632) 85548467

Email: dadelmundo@up.edu.ph

The authors declare that this represents original material, that the manuscript has been read and approved by all the authors, that the requirements for authorship have been met by each author, and that each author believes that the manuscript represents honest work.

Disclosures: The authors signed disclosures that there are no financial or other (including personal) relationships, intellectual passion, political or religious beliefs, and institutional affiliations that might lead to a conflict of interest.

Presented at the 2017 Philippine General Hospital Expanded Hospital Research Office (PGH-EHRO) Resident's Research Forum (3rd place), October 10, 2017, HRDD Training Room, Philippine General Hospital, Manila City.

\section{A Case Report of Maxillary Calcifying Epithelial Odontogenic Tumor in a Teenage Girl}

\begin{abstract}
Objective: To report the case of a rare benign odontogenic tumor in an adolescent girl which was successfully managed by complete excision and curettage of underlying bone.

\section{Methods:}

Design: Case Report

Setting: Tertiary National University Hospital

Patient: One

Result: A 15-year-old girl with a 3-year history of a large Calcifying Epithelial Odontogenic Tumor (Pindborg Tumor) atypically occurring in the posterior maxillary alveolar ridge and compressing the maxillary antrum underwent tumor excision via gingivobuccal approach and curettage of the remaining mucosa in the cavity in consideration of her patient's aesthetic concerns. No recurrence has been observed two years post-op and she remains asymptomatic on regular follow-up.
\end{abstract}

Conclusion: A calcifying epithelial odontogenic tumor can be managed conservatively with close follow-up to monitor recurrence.

Keywords: calcifying epithelial odontogenic tumor; Pindborg tumor; conservative surgery; adolescent

When planning to perform surgical excision of a mass that could potentially alter maxillofacial growth of a pediatric patient, one must be knowledgeable of the histology and clinical behavior of the disease entity encountered, in order to plan the most conservative approach that will yield a desirable outcome. This case highlights the successful removal of a maxillary Pindborg tumor in a young female with excision and curettage. 


\section{CASE REPORT}

A 15-year-old girl presented in our hospital with an enlarging left upper alveolar mass that evolved over three years. She initially consulted the dentistry service for a painless pea-sized gingival mass that radiographically appeared as a unilocular radiolucency extending from the second premolar to the first molar in the left maxillary alveolar ridge. Incision biopsy revealed an eruption cyst which was marsupialized.

A year later, the patient noted recurrence of the mass in the previous surgical site. A panoramic radiograph showed mixed radioopacities and radiolucencies. Computed tomography revealed an expansile unilocular osseous lesion with multiple calcific densities at the alveolar aspect of the left lateral maxilla, compressing the left maxillary sinus supero-medially towards the orbital floor. (Figure 1) She was referred to otorhinolaryngology for incision biopsy, which yielded findings consistent with calcifying epithelial odontogenic tumor.

Upon admission, the patient had obvious enlargement of the left cheek, stretching the skin without causing any induration or ulcerations. In the oral cavity, the mass appeared as a $5 \times 4 \times 3 \mathrm{~cm}$ firm, multilobulated, movable mass occupying the area from the first premolar to the second molar of the left maxillary alveolar ridge and abutting the buccal mucosa laterally and medially overhanging towards the hard palate.

Rather than perform a lateral rhinotomy to achieve optimal exposure, the patient's aesthetic concerns were considered, and the mass was completely excised intra-orally through a gingiva-buccal incision, leaving a cavity in the expanded but intact alveolar ridge. Curettage removed the remaining mucosa and a thin portion of underlying bone. (Figure 2) Final histopathologic examination confirmed the diagnosis of Pindborg Tumor. (Figure 3) The patient has been on follow-up for two years with marked improvement in the symmetry of her face, and no note of recurrence at the surgical site. (Figure 4)
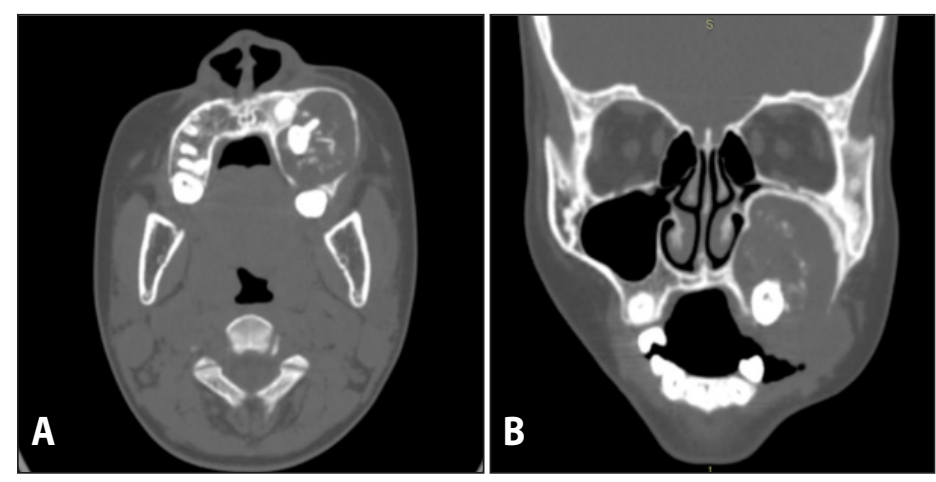

Figure 1. A. Representative axial Computed Tomography (CT) image showing a soft tissue mass with irregular calcific densities and an imbedded unerupted tooth occupying the space where the maxillary sinus should have been; B. Representative coronal Computed Tomography (CT) image showing the mass extending inferiorly below the occlusal line and laterally into the gingivobuccal sulcus, with its superior aspect pushing the floor of the maxillary sinus upwards but without causing dehiscence.

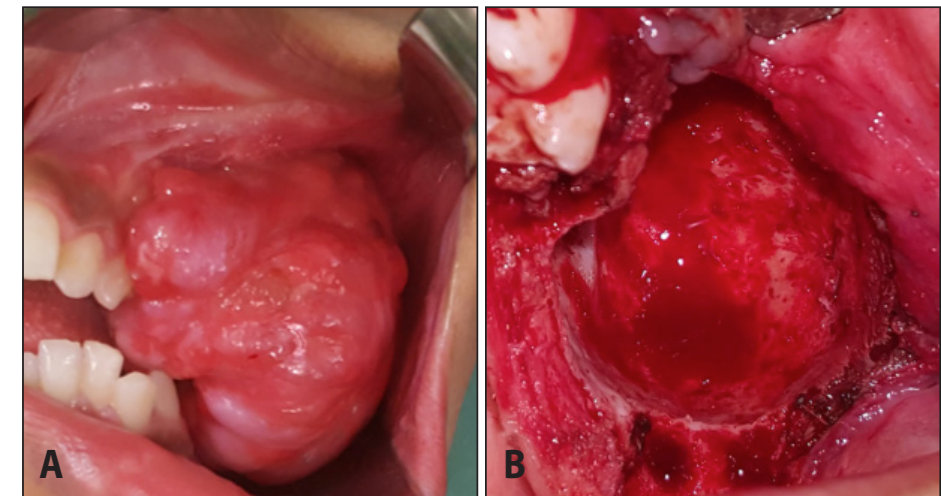

Figure 2. A. Intraoperative images showing a well-encapsulated, nodular intra-oral mass expanding the left maxillary alveolar ridge; B. Excision via blunt dissection revealed an expanded cavity on the alveolar ridge, but the floor of the maxillary sinus was intact.
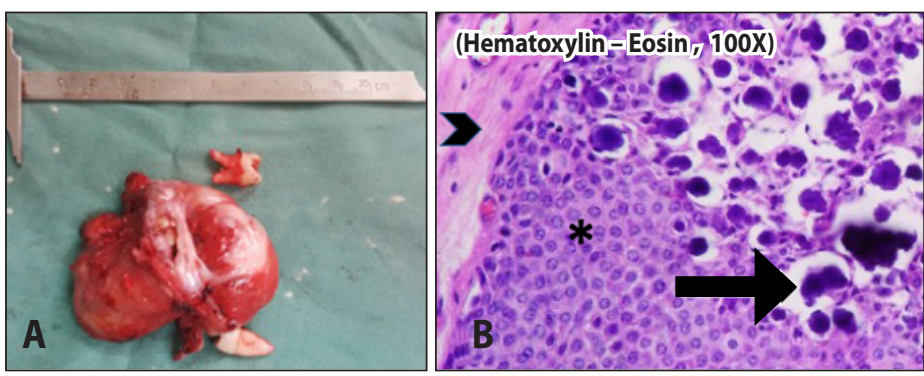

Figure 3. A. Gross specimen consisting of a $7 \times 7 \times 4 \mathrm{~cm}$ firm nodular well-encapsulated mass with left canine and molar; B. Sheets of eosinophilic, polyhedral cells in a cribriform pattern with welldefined cell borders and distinct intercellular borders (asterisk), with Liesegang calcification (arrow) and amyloid-like material (arrowhead). (Hematoxylin-Eosin, 100X magnification)
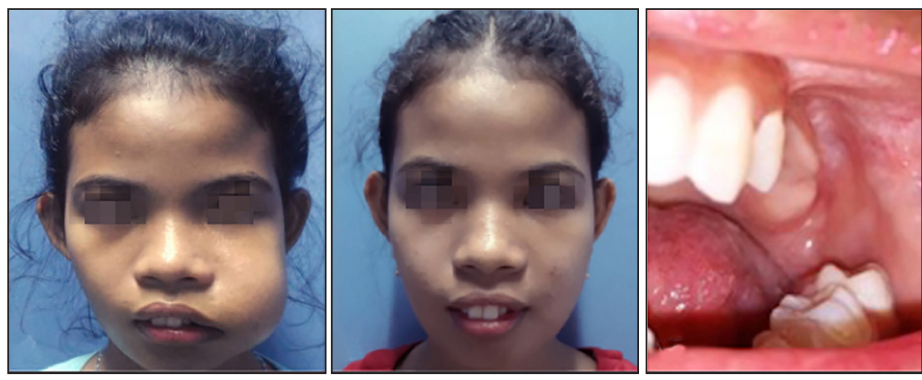

Figure 4 A.Frontal image taken pre-operatively; B. Frontal image taken 2 years post-operatively C. Intra-oral image taken 2 years post-operatively showing good mucosal healing, decrease in the size of the surgical cavity and no tumor recurrence.

\section{DISCUSSION}

The Calcifying Epithelial Odontogenic Tumor (CEOT) was first described in 1955 by Dutch pathologist Jens Jorgen Pindborg. 'It is a benign expansile slow-growing neoplasm which behaves clinically like an ameloblastoma but has a lower rate of recurrence. It has a peak incidence in the age range of 40-60 years, with no apparent sex predilection and a greater tendency to appear in the mandible rather than the maxilla, with a ratio of 3:1.2 The central or intraosseous variant is more common and is described in approximately $96 \%$ of documented cases, while the peripheral or extraosseous variant comprises the remainder. ${ }^{3}$ 


\section{CASE REPORTS}

Philippine Journal Of Otolaryngology-Head And Neck Surgery

Vol. 35 No. 2 July - DeCEMBER 2020

Early in its growth, CEOT may appear on radiograph as a unilocular radiolucency and becomes progressively more radio-opaque as calcium deposits start to accumulate. Subsequently, a mixed radio-lucent/radioopaque appearance can manifest as bone is simultaneously eroded. Furthermore, $60 \%$ of cases have been shown to involve an impacted tooth. This conglomeration of radiographic findings, all observed in this patient, may explain why such cases may easily be initially diagnosed and managed as an odontogenic cyst. ${ }^{4}$ This stresses that CEOT should not be left out of the differential diagnosis despite its rarity, as it may have a very similar appearance to more common entities.

Establishing the diagnosis of CEOT is dependent upon histopathologic features. Typically, there is scanty connective tissue stroma arranged in sheets of polyhedral epithelial cells surrounded by a homogenous eosinophilic material, thought to be amyloid. The pathognomonic finding is described as concentric calcifications within the amyloid substance, called "Leisegang rings."

Unlike the majority of CEOT this case occurs in a less common location, in an unusual age demographic, exhibiting both intraosseous and extraosseous components. Apart from the atypical features seen in this patient, perhaps the most important aspect of this case lies in the management dilemma it presents.

Lesions of the maxilla are known to be more locally invasive and grow more rapidly, possibly warranting more aggressive surgery. ${ }^{6}$ But in this case, we had an adolescent girl for whom aesthetic outcome was a major consideration, making it necessary to plan the least invasive and disfiguring surgery possible. In this unique situation there is only a small volume of available literature from which to draw recommendations.

A case report and literature review by Fazeli et al. outlined 14 cases of CEOT in pediatric patients, with only 4 occurring in the maxilla; 7 Ungari et al. performed enucleation and curettage of a $0.8 \mathrm{~cm}$ CEOT of the maxilla in a 9-year-old boy; ${ }^{8}$ Mopsik et al. documented intra-oral access and enucleation for a cystic CEOT of the maxilla in a 13-year-old girl; ${ }^{9}$ Gopalakrishnan et al. reported a large invasive cystic CEOT situated within the maxillary sinus itself which was enucleated via Caldwell-Luc approach; ${ }^{10}$ and Mandal et al. described a $6 \times 5 \mathrm{~cm}$ CEOT of the hard palate causing lytic changes in adjacent bony structures, although the type of excision was unspecified. ${ }^{11}$ No recurrence was documented for any of these cases, but follow-up periods for these cases ranged only from 1 month to 1 year. Perhaps the case most similar to ours was presented in a separate report by Tiwari, which involved a 12-year-old boy presenting with a 5-month history of cheek swelling due to a $6 \times 4$ cm maxillary CEOT. ${ }^{5}$ Excision was performed, and although there was no mention of curettage of underlying bone for additional margins, the patient likewise exhibited no recurrence after 2 years of follow-up. ${ }^{5}$

There is some evidence suggesting that CEOT does not infiltrate inter-trabecular bony spaces, supporting the consideration of enucleation and curettage of thin remaining bone. However, these reports involved less aggressive tumors found in the mandible. ${ }^{12}$ It has been postulated that certain histologic features such as the presence of more amyloid and calcific tissue, in contrast to more clear cells, confers less aggressive potential. ${ }^{5}$ Recommendations regarding radicality of surgery vary due to the unpredictable behavior of CEOTs, but most authors are in agreement that it is imperative to achieve tumor-free hard and soft surgical margins to minimize recurrence. ${ }^{6}$

In our case, the decision to adapt a more conservative surgical approach was arrived at by weighing the risk of recurrence against leaving an unsightly scar on a young face, which could yield detrimental psychological effects. In the absence of clear-cut recommendations, the patient's wish for a better aesthetic outcome took precedence. As a compromise, close follow-up was planned in order to facilitate early detection of possible recurrence, which is said to be 10 to $20 \%$ following conservative management. ${ }^{6}$ Fortunately, good healing and no sign of recurrence has been observed in the last two years of follow-up. There is a need to further document the longterm outcomes of CEOT, and the occurrence of these tumors in the pediatric population presents that opportunity.

\section{ACKNOWLEDGEMENTS}

The authors would like to acknowledge Dr. Dahlia Teresa R. Argamosa, Dr. Erick Martin H. Yturralde and Dr.Marvin C. Masalunga, our colleagues from the Pathology Section of the Philippine General Hospital Department of Laboratories for providing photodocumentation of the histopathologic slides.

\section{REFERENCES}

1. Akhtar K, Khan N, Zaheer S, Sherwani R, Hasan A. Pindborg Tumor in an Adolescent. Oman Med J. 2010 Jan; 25(1):47-8. DOI: 10.5001/omj.2010.12; PubMed PMID: 22125699; PubMed Central PMCID: PMC3215391.

2. Shah KS, Butt FMA, Dimba EAO. Case Report: Calcifying epithelial odontogenic tumor (Pindborg tumor). Anat J Afr. 2015 Jul; 2 (2): 135-136. Available from http://www.anatomyafrica.com/ Vol2issue2/kshah.pdf.

3. Singh N, Sahai $S$, Singh $S$, Singh S. Calcifying epithelial odontogenic tumor (Pindborg tumor). Nat J Maxillofac Surg. 2011 Jul-Dec; 2(2): 225-227. DOI: 10.4103/0975-5950.94489; PubMed PMID: 22639521 PubMed Central PMCID: PMC3343415.

4. Halaj-Mofrad A, Rajabi M, Dabiri S. Calcifying epithelial odontogenic (Pindborg) tumor involving a 16-year-old girl with no prominent clinical manifestation: A case report. J Oral Health Oral Epidemiol. 2015 Feb; 4(1): 51-57. Available from: http://johoe.kmu.ac.ir/article_84816.html.

5. Tiwari M. 12 Year Pediatric Patient Having Pindborg Tumour an Intraosseous Variant: A Rare Case Presentation Affecting the Maxilla. Oral Health Case Rep. 2016 Mar.2(1). DOI:10.4172/ OHCR.1000109.

6. Rani V, Masthan MK, Aravindha B, Leena S. Aggressive Calcifying Epithelial Odontogenic Tumor of the Maxillary Sinus with Extraosseous Oral Mucosal Involvement: A Case Report. Iran J Med Sci. 2016 Mar. 41(2): 145-149. PubMed PMID: 26989286 PubMed Central PMCID: PMC4764965.

7. Fazeli S, Giglou K, Soliman M, Ezzat W, Salama A, Zaho Q. Calcifying Epithelial Odontogenic (Pindborg) Tumor in a Child: A Case Report and Literature Review. Head and Neck Pathol. 2019 Dec; 13(4): 580-586. DOI: 10.1007/s12105-019-01009-1; PubMed Central PMCID: PMC6853849.

8. Ungari C, Poladas G, Giovannetti F, Carnevale C, lanetti G. Pindborg tumor in children. $J$ Craniofac Surg. 2006 Mar; 17(2):365-9. DOI: 10.1097/00001665-20060300-00029; PubMed PMID: 16633191.

9. Mopsik E, Gabriel S. Calcifying epithelial odontogenic tumor (Pindborg tumor). Report of two cases. Oral Surg Oral Med Oral Pathol. 1971 Jul; 32(1):15-21. DOI: 10.1016/0030-4220(71)90245-3; PubMed PMID: 5281552

10. Gopalakrishnan R, Simonton S, Rohrer M, Koutlas I. Cystic variant of calcifying epithelial odontogenic tumor. Oral Surg Oral Med Oral Pathol Oral Radiol Endod. 2006 Dec; 102(6):773-7. DOI: 10.1016/j.tripleo.2005.09.029; PubMed PMID: 17138180.

11. Mandal S, Varma K, Khurana N, Mandal A. Calcifying epithelial odontogenic tumor: report of two cases. Indian J Pathol Microbiol. 2008 Jul-Sep; 51(3):397-8. DOI: 10.4103/0377-4929.42529; PubMed PMID: 18723969.

12. Vigneswaran T, Naveena R. Treatment of calcifying epithelial odontogenic tumor/Pindborg tumor by a conservative surgical method. J Pharm Bioallied Sci. 2015 Apr; 7 (Suppl 1): S2915. DOI: 10.4103/0975-7406.155961; PubMed PMID: 26015736 PubMed Central PMCID PMC4439696. 